\title{
Postmethod Pedagogy and Its Influence on EFL Teaching Strategies
}

\author{
Mingyao Chen ${ }^{1}$ \\ ${ }^{1}$ School of Foreign Languages, Zhejiang Gongshang University, China \\ Correspondence: Mingyao Chen, School of Foreign Languages, Zhejiang Gongshang University, Hangzhou, \\ Zhejiang, 310018, China. Tel: 86-138-5818-8329. E-mail: chenmingyao@hotmail.com
}

Received: January 20, 2014 Accepted: February 28, 2014 Online Published: April 14, 2014

doi:10.5539/elt.v7n5p17 URL: http://dx.doi.org/10.5539/elt.v7n5p17

\begin{abstract}
Postmethod pedagogy is first put forward by Kumaravadivelu in 1994. It emerged to respond the demand for a most optimal way of teaching English free from the method-based restrictions. Kumaravadivelu views postmethod pedagogy as a three dimensional system with three pedagogic parameters: particularity, practicality, and possibility; and he proposes micro-strategies in EFL classrooms. To better illustrate his theory and its influence on EFL teachers' teaching strategies, it is necessary to conduct case studies in schools to investigate both teachers' and students' beliefs about methods and postmethods, and to find out whether the current teaching activities are in accordance with the micro-strategies of postmethod pedagogy in terms of teaching interaction, teaching technique, teaching object and teaching content. Then this paper goes on to summarize the implications of this study for teaching and teacher education.
\end{abstract}

Keywords: postmethod pedagogy, EFL teaching, teaching strategies

\section{Introduction}

ELT has been developing rapidly in the recent 100 years. However, quality problems and unsatisfactory learning outcome push teachers and pedagogical researchers to search for effective methods. Various methods, such as oral approach, audio lingual method, contend-based teaching, communicative approach, flourish. As Kumaravadivelu points out, one might think that the methods listed above provide different pathways to language learning and teaching. That is not the case. In fact, there is considerable overlap in theory and practice (2006, p. 163). What appears to be a radically new method is more often than not a variant of existing methods presented with the fresh paint of a new terminology that camouflages their fundamental similarity (Rivers, 1991, p. 283). According to Marckwardt, these changing winds and shifting sands are like a cyclical pattern in which a new paradigm of teaching methodology emerged about every quarter of a century, with each new method breaking from the old but at the same time taking with it some of the positive aspects of the previous paradigm. Almost every established method claims to be better than the previous ones. Yet none can prove its optimal quality and is recommended as the most appropriate for ELT convincingly. They have now and then been criticized as unproductive and misguided (Stern, 1985, p. 251), a label without substance, relative unhelpful (Allright, 1991, p. 1) and even a dead method (Allright, 1991; Brown, 2002, p. 11). Kumaravadivelu concludes that the concept of method has little theoretical validity and even less practical utility. The deep discontent with the concept of method accumulating for a considerable length of time has finally resulted in the emergence of the postmethod pedagogy (2006, p. 170)

To find out the influence of postmethod pedagogy on ELT, we conduct a case study in a junior middle school to investigate the effect in actual practice.

\section{Literature Review}

\subsection{Understanding Postmethod Pedagogy}

Starting in the 1990s, teachers and researchers came to realize that no single research finding and no single method of language would bring final success in foreign language teaching (FLT) (Brown, 2002). Owing to the influence of post-modernism, the postmethod pedagogy emerged to respond the demand for a most optimal way of teaching English free from the method-based restrictions.

In 1994 Kumaravadivelu defined postmethod condition as a state of affairs that forces us to refigure the relationship between the theorizers and the practitioners. He explained that "the conventional concept of method 
entitles theorizers to construct knowledge-oriented pedagogic theories, while the postmethod condition enables the practitioners to construct classroom-oriented theories of practice. The conventional method authorizes theorizers to centralize pedagogic decision making, while the postmethod condition enables practitioners to produce local, specific, and novel practices" (Kumaravadivelu, 1994, p. 29).

The postmethod condition has three distinct features for redefining the relationship between the periphery and the center. The first feature is that it is a search for an alternative to method rather than an alternative method. The second feature is teacher autonomy. Teachers have the potential to know how to teach, to be able to handle problems within constrains. Promoting teacher autonomy means enabling and empowering teachers to theorize from their practice and practice what they have theorized (ibid, p. 30). The third feature is principled pragmatism. By "principled pragmatism" Kumaravadivelu explains that it is different from eclecticism, which often "degenerates into an unsystematic, unprincipled, and uncritical pedagogy because teachers with very little professional preparation to be eclectic in a principled way have little option but to randomly put together a package of techniques from various methods and label it eclectic" (ibid, p. 30).

Kumaravadivelu uses the term pedagogy in a broad way, intending to cover not only issues about classroom strategies, instructional materials, curricular objectives, and evaluation measures, but also many historical, political and sociocultural experiences that more or less influence ELT. He then visualizes a postmethod pedagogy as a three-dimensional system made up of three pedagogic parameters: particularity, practicality, and possibility (Kumaravadivelu, 2001, pp. 537-538). He takes method as consisting of a single set of theoretical principles derived from feeder disciplines and a single set of classroom procedures directed at classroom teachers (Kumaravadivelu, 1994, p. 29). Nilufer Can claims that "postmethod can be defined as the construction of classroom procedures and principles by the teacher herself/himself based on his/her prior and experimental knowledge and/or certain strategies." Kumaravadivelu (1994, p. 24) reaffirms that the concept of method involves theorizers constructing knowledge-oriented theories of pedagogy and post-method involves practitioners constructing classroom-oriented theories of practice. Cheng (2006) gives a rather comprehensive interpretation about postmethod pedagogy: flexible, dynamic and open-ended teaching concept different from any traditional approaches of language teaching. It opposes the practices of simplifying FLT and emphasizes its complexity. It heightens the importance of context sensitivity in FLT, and stresses that society, politics and education system have an important effect on FLT.

The three pedagogic parameters, particularity, practicality, and possibility, interact with each other in a synergic relationship. The parameter of particularity requires that any language pedagogy must be sensitive to a particular group of teachers teaching a particular group of learners pursuing a particular set of goals within a particular institutional context embedded in a particular sociocultural milieu (Kumaravadivelu, 2003, pp. 33-34). Local educational, institutional and social contexts have to be duly considered. The parameter of practicality refers to the relationship between theory and practice and the practice of classroom teaching. If the theory and practice are separated, and the theorist's role is greater than the teacher's, then it means that the teacher's potential to generate theories from practice and her/his potential to put theories into practice are overlooked. Kumaravadivelu (2003, p. 36) claims that the pedagogy of practicality seeks to enable teachers themselves to theorize from their practice and practice what they theorize. The parameter of possibility mainly comes from the educational philosophy of the Brazilian critical pedagogists, Paulo Freire. He and his fellow researchers point out that any pedagogy is closely connected with power and dominance, and is implemented to create and sustain social inequalities. They call for the recognition of learners' and teachers' subject-positions, i.e. their class, race, gender and ethnicity, and for sensitivity toward their impact on education. The awareness learners bring to pedagogical settings are not only influenced by what they learn from the classroom, but also are cultured by a broader social economic, and political environment in which they grow up. Such awareness may alter pedagogic practices in ways unintended and unexpected by policy planners, curriculum designers, or textbook compilers.

The boundaries of the three parameters are unclear and the characteristic features of these parameters overlap. They shape and are shaped by one another. They interact with each other. They together constitute the conceptual foundation for the postmethod.

\subsection{The Indicators of Postmethod Pedagogy}

The major indicators of Postmethod Pedagogy are the learner, the teacher, the teacher educator. From the perspective of postmethod pedagogy, the learner is active and autonomous. Kumaravadivelu (2001) suggests the three aspects of the learner autonomy: academic, social and liberatory; and then, in 2006, he proposes two types: academic and liberatory.

Kumaravadivelu considered the academic view as a narrow view which seeks to develop in the learner a capacity 
to learn while the broad view, liberatory, goes beyond that to include a capacity to learn to liberate at the same time. According to him, learning to learn means learning to use appropriate strategies to realize desired objectives. By using appropriate strategies, learners are able to monitor their learning process and maximize their learning potential. If academic autonomy enables learners to be effective, liberatory autonomy empowers them to be critical thinkers. Therefore, liberatory autonomy goes further actively helping learners reflect on themselves and their social world, form their learning communities, and provide them opportunities and possibilities for exploration. Thus, learners will be more prepared for better solutions to problems in learning. However, learners will only be able to achieve such a goal with the help of others, and particularly, their teachers.

The postmethod pedagogy considers the teacher as an autonomous teacher. This autonomy is central and is in fact the heart of postmethod pedagogy (Kumaravadivelu, 2006, p. 179). Postmethod pedagogy recognizes the teacher's previous and current knowledge, and their potential to teach and act autonomously, which promotes the ability of the teacher to know how to develop a reflective approach to his own teaching, how to analyze and evaluate his own teaching acts, how to initiate change in his classroom, and how to monitor the effects of such changes (Wallace, 1991). Such ability can evolve only if the teacher has a desire and a determination to maintain a fair degree of autonomy in pedagogic decision making. The teacher has to rely on his prior and evolving personal knowledge of learning and teaching in order to break away from the constraining concept of method. This knowledge not only involves particular classroom handling, but also involves connecting cognitive thinking with action. It evolves through determined efforts. What postmethod pedagogy assumes is that this kind of personal knowledge the teacher develops over time will eventually lead them to construct their own theory of practice (Kumaravadivelu, 2006).

The task of the postmethod teacher educator is to create conditions for prospective teachers to acquire necessary authority and autonomy that will enable them to reflect on and shape their own pedagogic experiences, and in certain cases transform such experience (Kumaravadivelu, 2006, p. 182). Through a series of dialogic interactions, channels of communication between student-teachers and teacher-educators open up. They actively exchange ideas. The teacher educators will then show a willingness to use the student teachers' values, beliefs and knowledge as an integral part of the learning process. The entire process of teacher education eventually becomes reflective and rewarding.

\subsection{Postmethod Strategic Framework}

According to Kumaravadivelu (2003b), the postmethod strategic framework for language teaching consists of macrostrategies and microstrategies. He defines macrostrategies as guiding principles derived from historical, theoretical, empirical, and experiential insights related to L2 learning and teaching. A macrostrategy is a broad guideline leading teachers to generate their own location-specific, need-based microstrategies or classroom procedures.

The strategic framework cover ten macrostrategies expressed with operational terms that convey no prescriptive quality. They are: (1) Maximize learning opportunities. This strategy envisages teaching as a process of creating and utilizing learning opportunities. The teacher is seen both as a creator of learning opportunities for his learners and the utilizer of learning opportunities created by learners. (2) Minimize perceptual mismatches. This strategy stresses the recognition of potential perceptual mismatches between intentions and interpretations of the learner, the teacher, and the teacher educator. (3) Facilitate negotiated interaction. This strategy means the meaningful learner-learner, learner-teacher classroom interaction where learners are entitled and encouraged to propose topic and initiate talk, not merely react or respond. (4) Promote learner autonomy. This strategy refers to helping learners learn how to learn, equipping them with the means necessary to self-direct and self-monitor their own learning. (5) Forster language awareness. This strategy involves any attempt to draw learners' attention to the formal and functional properties of their L2 in order to increase the degree of explicitness required to promote L2 learning. (6) Activate intuitive heuristics. This strategy stresses the importance of providing rich textual data so that learners can infer and internalize underlying rules governing grammatical usage and communicative use. (7) Contextualize linguistic input. This strategy highlights how language usage and use are shaped by linguistic, extralinguistic, situational and extrasituational contexts. (8) Integrate language skills. This macrostrategy refers to the need to holistically integrate language skills traditionally separated and sequenced as listening, speaking, reading, and writing. (9) Ensure social relevance. This strategy stresses the need for the teacher to be sensitive to the societal, political, economic, and educational environment in which L2 learning and teaching take place. (10) Raise cultural consciousness: This strategy stresses the need to treat learners as cultural informants so that they are encouraged to engage in a process of classroom participation that puts a premium on their power/knowledge. 
The macrostrategies introduced above are general guiding principles for classroom teaching, and are to be implemented in the classroom through microstrategies designed to realize the goals of a particular macrostrategy. One macrostrategy may have many microstrategies. Microstrategies refer to "classroom procedures that are designed to realize the objectives of a particular macrostrategy. Any type of microstrategy depends on the local learning and teaching situation. The possibilities are endless" (Kumaravadivelu, 2006). Microstrategies are associated with different local situations and conditioned by the national, regional, or local language policy and planning, curricular objectives, institutional resources, and learners' needs, wants, lacks as well as their current level of language knowledge/competence, and a great many other possible factors. As for detailed microstrategies following each macrostrategy, Kumaravadivelu mentions opportunities outside classroom for the first one, learner training and learner perception for the second, intensive teacher-learner communication for the third, learner autonomy and learning preferences for the fourth, language use and language awareness for the fifth and the sixth, contextualizing linguistic input for the seventh, utilizing all sorts of raw materials for the eighth, ensuring social and cultural relevance for the ninth and tenth. In fact, Kumaravadivelu has demonstrated a comprehensive picture of how to design valid microstrategies in a specific context under the guidance of each macrostrategy.

\section{Research Method}

\subsection{Strategies Studied in This Research}

Based on Kumaravadivelu's postmethod framework, four strategy categories are under consideration in this research: teaching interaction, teaching technique, teaching objective and teaching content.

For the first one, teaching interaction, three macrostrategies are involved, namely, maximizing learning opportunities, facilitating negotiated interaction, and minimizing perceptual mismatches. In this respect, this research is to discuss related microstrategies such as the ways to learn English, the situation of answering questions in class, teachers' responses to questions, students' responses to teachers, etc.

For the second, teaching technique, three macrostrategies are concerned, namely, activating intuitive heuristics, contextualizing linguistic input, and integrating language skills. Related microstrategies in this research are students' enlightenment and encouragement from teachers, the status quo of situational teaching, students' best and worst skill in English learning.

For the third, teaching objective, two macrostrategies are involved, namely, promoting facilitating learner autonomy, and fostering language awareness. This research is to discuss related microstrategies such as students' status quo of reviewing, reading non-taxtbook English materials and making learning plans, student's attitude toward language use and awareness.

For the fouth, teaching content, two macrostrategies are concerned, raising cultural consciousness and ensuring social relevance. The researcher will discuss the teacher's explanation about culture and the student's motivation of learning English.

\subsection{Research Questions}

Traditionally, teachers like to adopt different teaching methods in EFL classrooms. Most of us are generally curious about new methods and are interested in trying them in class. We hardly stop to think about their imperfection. Postmethod pedagogy allows us to go beyond, and overcome the limitations of method-based pedagogy (Kumaravadivelu, 2006).

By investigating the status quo of ELT in a junior middle school in China, this research concerns both teachers' and students' beliefs about methods and postmethods. It aims to answer the following questions in particular:

In terms of teaching interaction, teaching technique, teaching objective and teaching content, what teaching activities in the case study are in conformity with the microstrategies of postmethod pedagogy?

What are the problems in the current teaching activities from the view of postmethod pedagogy?

\subsection{Research Subjects}

In this study three EFL teachers of Grade Eight were selected from Wenlan Junior Middle School in Hangzhou, China. The first subject, Teacher A, is a female teacher with 25 years of teaching experience, an MA degree holder in ELT. The second one, Teacher B, is a young female practitioner, a BA degree holder, with only 5 years teaching experience. The third one, Teacher $\mathrm{C}$, is a male novice teacher with only one year experience in teaching, a BA degree holder.

All these teachers teach students from Grade Eight, the second year in the junior middle school. They have 
already adapted themselves to the junior middle school life and they do not have the pressure of graduation, as in China students generally stay for three years of study before taking the important entrance examination for the senior middle school, which is a great pressure for all graduating students and their teachers. The students selected for this study are around the age of 15. They have learned English for around 5 years in public schools and have picked up some strategies in learning English.

\subsection{Research Instrument and Data Collection}

This study uses questionnaire, semi-structured interview and class observation as the main research instruments. The three teaching parameters and the macrostrategic framework of postmethod pedagogy are used as the guiding principles for the design of interviews and questionnaires.

The questionnaire contains 20 questions based on the ten macrostrategies, with 7 close-ended questions and 3 open-ended ones. They are divided in four parts, written in Chinese. Questions 1-5 are about interactive teaching, designed to examine whether the interactive activities in the classroom meet the requirements of the three macrostrategies, i.e. maximizing learning opportunities, facilitating negotiated interaction, and minimizing perceptual mismatches. Questions 6-9 are about teaching techniques, designed to examine the feasibility o fthe principles of the three macrostrategies, i.e. activating intuitive heuristics, contextualizing linguistic input, and integrating language skills. Questions 10-15 are designed to investigate what and how the students understand the teaching objectives, i.e. promoting learner autonomy, and fostering language awareness. Questions 16-17 are about teaching content, concerning cultural consciousness and ensuring social relevance. Question 18 is about students' use of strategies and Question 19 is about teaching method evaluation. Question 20 is about students' preference for certain methods that their teachers will use in the classroom. 240 questionnaires were distributed and 236 were anonymously completed and retrieved as effective.

The three teachers are individually interviewed for freedom of speech. The whole processes are recorded and transcribed in Chinese.

This research also adopts class observation as a supplementary method, which may help prove the reliability of the data obtained from the interview and questionnaire. The observation processes are all recorded and transcribed.

\section{Results and Discussion}

\subsection{Results of the Questionnaire}

A total of 240 questionnaires were distributed and 236 were completed and collected. The results are here presented in the four parts as are designed.

1) About teaching interaction:

a) 126 students, about $53.4 \%$, claim that they like to read non-text English materials such as stories or newspapers, in order to learn English better. 112 students, about $47.5 \%$, claim that they like to go to English training schools to learn more English. 88 students, about $37.3 \%$, claim that they like to use the Internet to learn more English. 28 students, about $11.9 \%$, claim that they would like to take part in the school activity to learn English.

b) 156 students, about $66.1 \%$, answer questions when asked; $21.2 \%$ answer questions voluntarily; $12.7 \%$ are reluctant.

c) 130 students, about $55.1 \%$, state that their teachers would answer and explain students' questions. $23.4 \%$ state that their teachers are reluctant to answer their questions if not relevant to the class. $19.5 \%$ state that their teacher would not answer non-relevant questions.

d) $67.8 \%$ of the students discuss their own doubts or questions with their peers. Only $25.1 \%$ state that they usually ask questions to their teachers.

e) $57.6 \%$ of the students state that their teachers give them clear explanation about their teaching plans and objectives. $33.1 \%$ state that that the teacher sometimes tell them some plans. 9.3\% students say their teachers never tell them anything about their plans.

2) About teaching technique:

a) $88 \%$ of the students state that they get clear instruction from the teacher and also great encouragement

b) $65.3 \%$ of the students state that their teachers often create situational context for their language practice.

c) $53.4 \%$ of the students claim that their best skill is in reading, $22 \%$ listening, $15.3 \%$ speaking, $8.5 \%$ writing. 
d) $45.8 \%$ of the students claim that they are very poor in grammar, 23.7 poor in speaking, 18.6 poor in memorizing vocabulary, 11.9 in reading comprehension.

3) About teaching objective

a) $86.3 \%$ of the students state that their teachers teach them learning skills

b) $70.3 \%$ of the students review what they have learned in the English class

c) $53.4 \%$ of the students sometimes read English books other than the textbook

d) $50.3 \%$ of the students would like to learn some English if there were no chance at school

e) $83.1 \%$ of the students state that language awareness plays a vital role in the English learning process

4) About teaching content

a) $44.1 \%$ of the students state that their teachers sometimes teach them culture knowledge about English-speaking countries. $40.7 \%$ of students state that their teachers often teach them culture knowledge about English-speaking countries.

b) $32.3 \%$ of the students state that they learn English for going abroad; $29.7 \%$ for a high score in the senior middle school entrance examination, $18.6 \%$ for self-development in this developing country, $15.3 \%$ for their interest in English

\subsection{Discussion about the Questionnaire}

Concerning teaching interaction, the results seem to indicate about half of the students would like to do out-of-class reading, go to English training schools, and use the Internet to learn English. These activities are in accordance with the microstrategies for maximizing learning opportunities. Only a small portion of the students like to take part in school activities for learning English, which probably implies that there are not enough interesting school activities for students. More opportunities are expected to meet their English learning demand. As for students' reluctance to answer questions in class, it again indicates the questions are probably boring or too hard to answer. Therefore, teachers need to design better questions to trigger meaning interaction with the students. With the teacher's reluctance to answer students' irrelevant questions, this probably means a great hurt to students' thirst for learning, which is likely to lead to his hatred for the English teacher, and his English class as well. When teachers encounter students' questions, whether relevant or irrelevant, they should be ready to answer, or if too hard to answer immediately, to discuss, or try to lead the question into the English class in a flexible and intelligent way. It is the same with those questions concerning minimizing perceptual mismatches. More than half of the students (57.6\%) say that their teachers often tell them their teaching plans and objectives. This is reasonable, but the number is comparatively small. Still some teachers do not explain their objectives to the students which may lead to a big gap between the teacher's intention and the learner's interpretation, and eventually affect the English teaching quality and students' learning outcome.

In terms of teaching technique, questions 6-9 are designed to find out about the teacher's microstrategy of activating intuitive heuristics in English class. Most students (88\%) state that they could receive enlightenment and encouragement. To help with the students learning method and potential, teachers try to provide them with typical examples and clear explanation, so that student will continue their learning after class in their process of self-discovery. As for the microstrategy of contextualizing linguistic input, $65.3 \%$ of students state that their teachers will create situational context for their language understanding and practice. The classroom is often treated as a speech community for interactive conversation or role play. With the microstrategy for integrating language skills we find different percentages among the students concerning their reading, writing, listening and speaking skills. That probably means that the teachers try to practice all these in class, not emphasizing one or ignoring another, as all these skills are important and related in language learning.

Concerning questions about students' reviewing after class, most students (70.3\%) do. And about half of the students also read non-textbook English materials. These show that teachers have tried to promote students' autonomous learning. As for fostering students' language awareness, most students (83.1\%) acknowledge that it is important and their teachers often stress it by doing exercises and pattern practices.

Regarding teaching content, $40.7 \%$ of the students state that their teachers often talk about the culture of English-speaking countries. This probably shows that these teachers need to put more stress on the culture aspect in class, as language is the carrier of culture, and some more cultural information will trigger more interest among the students in their English learning. Young students are generally curious about how other nations live, study, play or work. As for the microstrategy for ensuring social relevance, $32.2 \%$ of the students state that learning English is for going abroad, $29.7 \%$ for a high score, 18.6 for following the trend. Only $15.3 \%$ of the 
students express their interest in learning English, which is a sad fact for our English teachers. Teachers and teacher educators have to consider this result very seriously.

As for the last open questions concerning students' own skills in learning English, teachers' teaching methods, most students leave them blank. Probably they are still too young to summarize methods, or they think it is the task of the teacher to decide which method to adopt in class. Concerning the last question: What methods do you like your teachers to use in future English classes? Some students (38.8\%) mention games, videos, puzzles, etc. Others leave the question blank. This probably shows that students want to learn English in a more relaxed way. Grammar or collocation may be too serious, and teachers would need to find out better ways for their students in classroom learning, so as not to bore them.

\subsection{Discussion about the Interviews and Class Observation}

The three teachers are interviewed about their understanding and application of these strategies mentioned above. They all express their views in agreement with the mostmethod pedagogical strategies, such as maximizing learning opportunities, contextualizing linguistic input, promoting learner autonomy, raising cultural consciousness and ensuring social relevance. However, they are more or less puzzled by some strategies, such as perceptual mismatches between the teacher and the student. The youngest teacher, especially, mentions that he often ignores his students' irrelevant and sometimes ridiculous questions, or even criticizes them for not listening to his teaching. He has always hoped that students are obedient and will follow his instructions without caring about other things. If the students are reluctant to answer his questions and ask irrelevant questions instead, he sometimes gets angry with the students. The senior teacher seems more patient and shows more concern for the students' interest. Teacher B is in the middle. As a lady teacher, she is more patient than the young male teacher, but seems to have less experience in handling students' irrelevant questions when she does not know the answer. She only answers questions from her students when she is familiar with the topic. Teacher A never directly rejects her students demand. She will promise the students' to find out the answer even if she has no idea about a certain topic, say, football. When boys sometimes talk about football matches, and ask her which team may win the game in the evening, she would make a guess in English, and ask the boys to explain the reason. If the boys can say something in English, she will praise them at once. This experience is something later shared by the other two teachers in our discussion meeting when we report the results from our investigation to them.

For classroom observation, most of class activities are found teacher-centered, which is not in accordance with the postmethod strategy. Teachers explain texts and exercises most of the time, and students are passive receivers, making notes or correcting their mistakes in their homework. Teachers ask questions mostly concerning grammar, vocabulary or translation. Students have little chance practice what they have learned. When sometimes Teacher $\mathrm{B}$ and $\mathrm{C}$ do set some situations for students to do some role plays, students show little interest in them, as these role plays are usually strictly guided, and students have to practice certain words or pattern during the process. They have very little freedom in the play. This phenomenon is not in line with the learner autonomy proposed by the school. Teacher A's classroom is different. She is more concerned about learner autonomy. When she organizes class activities, she usually gives her students more freedom in performance. Once in her class, she gives them a topic, plays a short video clipping concerning the topic, and then asks her students to prepare a dialogue. Students discuss the topic freely. She gives comments on their performance, mostly with encouragement. And if students can use some words and patterns from the textbook, she will give them extra praise. Comparatively speaking, Teacher A's class is more active, while Teacher C's class is more serious, while Teacher B is in the middle. But Teacher B is very good at designing homework. She often gives students tasks or projects to do after class instead of traditional homework like translation or grammar practice. Students enjoy teamwork and often come back with their own English Class Papers, or picture with English captions, or some tricky English riddles they create. This way of designing homework is in line with the postmethod strategy of maximizing learning opportunity and promoting learner autonomy.

\section{Conclusion}

In this study, the researcher sets out to gain an understanding of the status quo of a junior middle school English teaching. With questionnaires, interviews and class observations, English teaching activities are discussed in detail concerning the postmethod strategies. During the process, some problems are also identified for teachers' attention.

Postmethod pedagogy provides us a new perspective to study the English language teaching and learning in the middle school. Regarding teaching interaction, the results seem to indicate that teachers should create more learning opportunities for the students. With more communication and understanding, teachers are highly expected to narrow the gap between the teacher intention and the learner interpretation, so as to minimize 
perceptual mismatches. In terms of teaching technique, teachers probably need to give students more encouragement before an activity, more freedom in an activity, and more praise after it. Contextualizing linguistic input is another way of language practice. Teachers may use whatever resources for students to learn, such as video, film, mp3, or anything at hand. In addition, language skills are related with one another, it is always wise to develop them in an integrated way. It is no good practicing listening or reading throughout the whole class. In terms of teaching objective, it is wise for the teachers to make every effort designing tasks for raising students' language awareness and promoting learner autonomy. As the saying goes, "don't give me fish, but teach me how to fish". Teachers should help students learn to use appropriate strategies to realize desired objectives. This is the objective of teaching. Academic autonomy is expected to enable learners to be effective learners and liberatory autonomy empowers them to be critical thinkers. As for the teaching content, more cultural background issues need to be brought up during the explanation of English texts. As language is the carrier of culture, an isolated textbook can never produce a talent. The teacher has to rely on his prior and evolving personal knowledge in order to break away from the constraining textbook alone. Culture knowledge of English speaking countries is not only necessary for text explanation, but also involves connecting cognitive thinking with the outside world.

Regarding English teaching in this junior middle, there are some problems worth our attention. Young teachers (as represented by Teacher C) probably need more exchanges of views and methods with senior teachers. Senior teachers may offer their help

We have discussed the postmethod theory in terms of the definition, its macrostrategic framework and microstrategies. We have reviewed previous researches and discussed the case study of a junior middle school in China. The results may not have general implication as the sample size is small. It is difficult to make generalizations about the data in qualitative analysis where there may have been insufficient evidence to back up claims in the part of discussion and conclusion. Besides, in our study, we have found that this concept of postmethod pedagogy is not very popular among the school teachers, though some of them keep trying these strategies for improving their teaching outcome. Anyway, they keep trying different strategies in their classroom, which is in line with teachers' autonomous decision-making proposed by postmethod pedagogy. Therefore, it is sincerely expected that more relevant researches will be carried out by middle school teachers themselves, more strategies will be designed and tested, and more discussion will come up in academic journals.

\section{References}

Allwright, R. L. (1991). The death of the method (Working Paper \#10). The Exploratory Practice Center, University of Lancaster, England.

Brown, H. D. (2002). English language teaching in the "Post-Method" era: Towards better diagnosis, treatment, and assessment. In J. C. Richards, \& W. A. Renandya (Eds.), Methodology in language teaching (pp. 9-18). Cambridge, England: Cambridge University Press.

Cheng, X. (2006). On the FLT method in postmethod era. Journal of Tianjin Institute of Foreign Languages, 7.

Kumaravadivelu, B. (2003). Beyond Methods: Macrostrategies for Language Teaching. [M] New Haven and London: Yale University Press.

Kumaravadivelu, B. (1994). The postmethod condition: Emerging strategies for second/foreign language teaching [J]. TESOL Quarterly, 28, 27-47.

Kumaravadivelu, B. (2001). Toward a Postmethod Pedagogy. TESOL Quarterly, 35, 537-560. http://dx.doi.org/10.2307/3588427

Kumaravadivelu, B. (2006). Understanding Language Teaching: From Method to Postmethod. London: Lawrence Erlbaum Associates.

Nilufer, C. (n.d.). Post-Method Pedagogy: Teacher Growth behind Walls. Proceedings of the 10th METU ELT Convention.

Rivers, W. M. (1991). The Psychologist and the Foreign Language Teacher. Illinois: University of Chicago Press.

Wallace, M. J. (1991). Training Foreign Language Teachers: A Reflective Approach. Cambridge: Cambridge University Press. 


\section{Copyrights}

Copyright for this article is retained by the author(s), with first publication rights granted to the journal.

This is an open-access article distributed under the terms and conditions of the Creative Commons Attribution license (http://creativecommons.org/licenses/by/3.0/). 